\title{
Accidental Ingestion of Petroleum in Children at the University Hospital of Brazzaville
}

\author{
Engoba Moyen ${ }^{1,2 *}$, Daniel Kazi Menga',3, Verlem Bomelefa-Bomel1, \\ Armel Landry Batchi-Bouyou', Georges Moyen'1 \\ ${ }^{1}$ University Marien Ngouabi, Brazzaville, Congo \\ ${ }^{2}$ Department of Intensive Care Pediatrics, University Hospital of Brazzaville, Brazzaville, Congo \\ ${ }^{3}$ Central Military Hospital, Brazzaville, Congo \\ Email: *engoba_m@yahoo.fr
}

How to cite this paper: Moyen, E., Kazi Menga, D., Bomelefa-Bomel, V., BatchiBouyou, A.L. and Moyen, G. (2021) Accidental Ingestion of Petroleum in Children at the University Hospital of Brazzaville. Open Journal of Pediatrics, 11, 1-8. https://doi.org/10.4236/ojped.2021.111001

Received: December 22, 2020

Accepted: February 4, 2021

Published: February 7, 2021

Copyright $\odot 2021$ by author(s) and Scientific Research Publishing Inc. This work is licensed under the Creative Commons Attribution International License (CC BY 4.0).

http://creativecommons.org/licenses/by/4.0/ Open Access

\begin{abstract}
Introduction: Petroleum ingestion is a health problem in Africa and can be responsible for significant mortality. Objectives: Improving the management of accidental petroleum ingestion in children, describe the socio-demographic characteristics, clinical, therapeutic and evolutionary profile of children hospitalized for accidental ingestion of petroleum and identify the factors associated with the occurrence of petroleum pneumopathy. Patients and Methods: We conducted a cross-sectional analytical study with retrospective collection from January 2016 to December 2015, i.e. in 24 months in the Pediatric Intensive Care and Infant Pediatrics departments at the University Hospital of Brazzaville. We included children who accidentally ingested petroleum. The variables studied were epidemiological, clinical, therapeutic, radiological and evolutionary. The statistical tests used were Pearson's $\mathrm{Chi}^{2}$ and Odds ratio. The materiality threshold was set at $5 \%$. Results: Out of 8013 children hospitalized, 78 (1\%) had accidentally ingested petroleum, including 49 (62.8\%) boys and 29 (37.3\%) girls with an average age of 20 months. They were between 13 and 30 months old $\mathrm{n}=44(56.4 \%)$. The mothers were between 25 and 35 years old $n=49(62.8 \%)$, no profession $n=31(39.7 \%)$ and secondary education level $n=49(62.8 \%)$. The mode of ingestion was self-ingestion (75.6\%). The place of occurrence was the family home (92.3\%). The motive of admission was breathlessness $\mathrm{n}=59(75.6 \%)$. An auscultation anomaly was noted $\mathrm{n}$ $=46(59 \%)$, a pneumopathy $n=43(55.1 \%)$. The treatment consisted of oxygen therapy $n=51(65.4 \%)$, antibiotic therapy $n=70(89.7 \%)$. The factors associated with the occurrence of a pneumopathy were: maneuvers performed and the existence of a cough. The lethality was $3.8 \%$. Conclusion: The high frequency of accidental petroleum ingestions in children with an outcome often marked by pulmonary complications and the related case fatality rate re-
\end{abstract}


quires primary preventive measures that rely on information, communication for behavior change with an emphasis on careful storage of toxic products and to refrain from harmful actions when faced with petroleum intoxication.

\section{Keywords}

Accidental Ingestion, Petroleum, Pneumopathy, Children, University Hospital of Brazzaville

\section{Introduction}

Ingestion of petroleum, most often accidental, is one of the most common household accidents among children in developing countries. Due to its frequency, it is a real public health problem [1] [2] with pneumonia as their most frequent complications [3]. The World Health Organization estimates the incidence of accidental poisoning in children under 15 at $282.4 / 100,000$, or $10.9 \%$ of all accidental injuries in children [4]. Ingestion of petroleum is rare or even exceptional in children in developed countries where reported cases mainly concern firebreathing adults [3] [5] [6]. In France, ingestion of kerosene represents $0.6 \%$ of cases and is responsible for $1 \%$ of pneumonias [7]. In Africa where oil is used as fuel or source of lighting, petroleum poisoning is very worrying: this is the case in Burkina Faso where it represents $54.5 \%$ of pediatric hospitalizations, it is also the case in Côte d'Ivoire: 22.5\%, 16.1\% in Gabon and 9.7\% in Mali [8] [9] [10] [11]. In Congo, petroleum ingestion accounts for $43 \%$ of accidental injuries in infants and $74 \%$ of acute poisonings in pediatric intensive care [1] [11].

With the aim of improving the management of children hospitalized for accidental ingestion of petroleum, the objectives of the study were: to describe the socio-demographic characteristics of children hospitalized for accidental ingestion of petroleum; describe the clinical, therapeutic and evolutionary aspects and identify the factors associated with the occurrence of petroleum pneumopathy.

\section{Patients and Methods}

The study was carried out in the pediatric department of the University Hospital of Brazzaville. This was a cross-sectional analytical study with retrospective data collection from January 2016 to December 2017, i.e. in 24 months.

We conducted the study on children hospitalized in the pediatric departmentregardless of their diagnoses. Those under 17 hospitalized for accidental ingestion of petroleum with available records were included. Newborns, ingestions of substances other than petroleum, and children aged 1 to 17 years old whose records were not usable were not included. The sample size calculated from Schwartz's formula [12] was 30 cases based on Ekouya's study [11]. A pre-established survey sheet as well as service files and registers were used for data collection.

The variables studied were: age, level of education and occupation of mothers; 
the age, sex of the child, circumstances of the occurrence (the place, time, method of ingestion, quantity ingested, maneuvers carried out and products administered at home), motive of admission, physical examination, blood count, radiological aspects, the treatment administered and the evolution profile, the amount ingested necessary to cause pneumonia by ingestion of petroleum was 1 $\mathrm{ml} / \mathrm{Kg}[13]$.

Data entry and analysis were performed using Epi info version 7 software. Qualitative variables were expressed as a percentage and quantitative as a median with interquartile range or as a mean with standard deviation. The comparison of the percentages was made with the Pearson's $\mathrm{Chi}^{2}$ test of independence and the Odds ratio (OR). The significance level was set at $5 \%$ and the confidence interval at $95 \%$.

\section{Results}

\subsection{Descriptive Study}

Out of 8013 children hospitalized during the study period, 91 (1.1\%) had a history accidental ingestion of petroleum, of which 78 met the inclusion criteria: $1 \%$ of hospitalizations. These were 51 children $(65.4 \%)$ hospitalized in the pediatric intensive care unit and $27(34.6 \%)$ in the infant pediatric unit. The average age was 20 months with the interquartile range: IQR [13 - 25.5]. They were one to 12 months old $n=19(24.4 \%) ; 13$ to 30 months $n=44(56.4 \%)$ and over 30 months $\mathrm{n}=15(19.2 \%)$. There were 49 boys $(62.8 \%)$ : aged one to 14 months $\mathrm{n}$ $=7(14.3 \%), 15$ to 30 months $\mathrm{n}=32(65.3 \%)$ and over 30 months $\mathrm{n}=10(20.4 \%)$ and $29(37.2 \%)$ girls: aged one to 14 months $\mathrm{n}=12(41.4 \%), 15$ to 30 months $\mathrm{n}=$ $12(41.4 \%)$ and over 30 months $\mathrm{n}=5(17.2 \%)$. Sex ratio of 1.7 (Table 1$)$.

The average age of the mothers was 29; IQR [25 - 34.7]. They were under 25 years old $n=17(21.8 \%)$, between 25 and 35 years old $n=49(62.8 \%)$, over 35 years old $\mathrm{n}=12(15.4 \%)$. They had an education level of secondary $\mathrm{n}=49$ $(62.8 \%)$, primary $n=24(30.8 \%)$ and university $n=5(6.4 \%)$. They were unemployed $\mathrm{n}=31(39.7 \%)$, informal sector workers $\mathrm{n}=26(33.4 \%)$, civil servant $\mathrm{n}=$ $17(21.8 \%)$ and student $\mathrm{n}=4(5.1 \%)$. The socioeconomic level was medium $\mathrm{n}=$ $43(55.1 \%)$ and low $\mathrm{n}=35(44.9 \%)$.

Table 1. Distribution by age group and sexe.

\begin{tabular}{ccccccc}
\hline & \multicolumn{2}{c}{ Garçons } & \multicolumn{2}{c}{ Filles } & \multicolumn{2}{c}{ TOTAL } \\
\cline { 2 - 7 } Tranches d'âge & $\mathbf{n}$ & $\%$ & $\mathbf{n}$ & $\%$ & $\mathbf{n}$ & $\%$ \\
\hline $1-14$ & 7 & 14.3 & 12 & 41.4 & 19 & 24.4 \\
$15-30$ & 32 & 65.3 & 12 & 41.4 & 44 & 56.4 \\
$>30$ & 10 & 20.4 & 5 & 17.2 & 15 & 19.2 \\
& 49 & 100.0 & 29 & 100.0 & 78 & 100.0 \\
\hline
\end{tabular}


The accidental mode of ingestion was self-ingestion $\mathrm{n}=59(75.6 \%)$ and administration by a third party $\mathrm{n}=19(24.4 \%)$. The ingestion occurred in the family home $\mathrm{n}=72(92.3 \%)$ and in neighbors $\mathrm{n}=6(7.7 \%)$ : between seven and 2 p.m. $\mathrm{n}=25(32 \%), 2$ and 6 p.m. $\mathrm{n}=34(43.6 \%)$ and 6 and 7 a.m. $\mathrm{n}=19(24.4 \%)$. The petroleum was kept in a drinking water bottle in all cases. The amount ingested, found in 69 cases $(88.5 \%)$ was considered toxic in 40 cases $(\mathrm{n}=51.2 \%)$. The maneuvers performed at home were: attempts to induce vomiting $\mathrm{n}=39$ (50\%), administration of milk $\mathrm{n}=51(65.4 \%)$, water $\mathrm{n}=16(20.5 \%)$, palm oil $\mathrm{n}=$ (5.1\%). The median consultation time was three hours. IQR [2 - 4.75]. It was minus six hours $n=66(84.6 \%)$ and over $n=12(n=15.4 \%)$

The reason for admission was difficulty breathing $\mathrm{n}=59$ cases $(75.6 \%)$, cough $\mathrm{n}=13(16.7 \%)$, vomiting $\mathrm{n}=5(6.4 \%)$ and one case of fever. The examination signs were: respiratory distress $n=61(78.2 \%)$, cough $n=33(42.3 \%)$, fever $n=$ $22(28.2 \%)$, coma $\mathrm{n}=18(23.1 \%)$, abdominal bloating $\mathrm{n}=2(2.6 \%)$, convulsion and restlessness in one case each. Respiratory distress was mild $\mathrm{n}=10(16.4 \%)$, moderate $\mathrm{n}=13(21.3 \%)$ and severe $\mathrm{n}=38(63.3 \%)$. Lung auscultation noted bronchial rales $n=27(60 \%)$, under crackles $n=14(31.1 \%)$ and crackles $n=4$ (8.9\%).

The complete blood count in 75 cases (96.2\%) noted hyperleukocytosis in 20 cases (26.7\%) and anemia in 27 cases (34.6\%). The CRP was done in 33 cases (42.3\%) and elevated in nine cases (27.3\%).

The chest X-ray, performed in all cases, was done during the first six hours $\mathrm{n}$ $=47$ cases $(60.3 \%)$ and beyond $n=31(39.7 \%)$. An abnormality was noted in 43 cases (55.1\%): bilateral $\mathrm{n}=16(37.2 \%)$, and unilateral $\mathrm{n}=27$ (34.6\%) with right involvement in 24 cases $(55.8 \%)$ and left three cases (7\%). This involved alveolar involvement $\mathrm{n}=29(67.4 \%)$, interstitial $\mathrm{n}=9(21.0 \%)$ and alveolar-interstitial $\mathrm{n}$ $=5(11.6 \%)$

The treatment consisted of oxygen therapy $\mathrm{n}=51(65.4 \%)$, antibiotic therapy $\mathrm{n}=70(89.7 \%)$ made with an amoxicillin $\mathrm{n}=63(80.8 \%)$, a third generation cephalosporin $\mathrm{n}=6(11.7 \%)$ and an amoxicillin-clavulanic acid combination $\mathrm{n}=3$ (3.8\%); corticosteroid therapy $\mathrm{n}=30(38.5 \%)$ and blood transfusion $\mathrm{n}=2$ (2.6\%).

The outcome was favorable in 35 children, pneumonia was noted in 43 cases (55.1\%) and one death in three of them (3.8\%) as a result of severe anemia: one case and following the severity of the respiratory distress: two cases. The median length of hospital stay was two days, with an interquartile range: IQR [2 3.7].

\subsection{Analytical Study}

The factors associated with the occurrence of petroleum pneumonitis were the quantity of petroleum ingested, the performance of certain maneuvers including induced vomiting, the administration of products including milk, the existence of cough and an auscultation anomaly (Table 2). 
Table 2. Factors associated with the onset of pneumopathy.

\begin{tabular}{|c|c|c|c|c|c|}
\hline & $\mathbf{n}$ & $\%$ & $\mathrm{p}$ & OR & IC 95 \\
\hline \multicolumn{6}{|l|}{ Age } \\
\hline$<30$ months & 35 & 81.4 & 0.9 & 1.1 & $0.3-3.4$ \\
\hline$>30$ months & 8 & 18.6 & & & \\
\hline Male & 25 & 58.1 & 0.3 & 0.6 & $0.2-1.6$ \\
\hline Female & 18 & 41.9 & & & \\
\hline Time to consultation & & & 0.4 & 0.6 & $0.2-1.8$ \\
\hline$<6$ hours & 31 & 72.1 & & & \\
\hline$>6$ hours & 12 & 27.9 & & & \\
\hline Quantity ingested & & & 0.02 & 3.4 & $1.2-9.8$ \\
\hline$>1 \mathrm{ml}$ & 31 & 79.5 & & & \\
\hline$<1 \mathrm{ml}$ & 8 & 20.5 & & & \\
\hline Induced vomiting & 31 & 72.1 & 0.001 & 8.7 & $3.1-24.4$ \\
\hline Ingested products & 35 & 81.4 & 0.001 & 5.1 & $1.9-14.4$ \\
\hline Cough & 16 & 37.2 & 0.02 & 2.8 & $1-8.3$ \\
\hline Pathological pulmonary auscultation & 31 & 72.1 & 0.02 & 3.8 & $1.4-10.1$ \\
\hline
\end{tabular}

\section{Discussion}

The current work on accidental ingestion of petroleum has some limitations, including the non-performance of blood gas measurement and bronchial endoscopy, the retrospective nature of the study, a source of data loss. However, it remains representative because of its size, its study setting, namely the pediatric departments of the University Hospital of Brazzaville, in particular the Pediatric Intensive Care department, the only department in the whole city with sufficient capacity to manage such emergencies in infants and children. These aspects give credibility to our results with the possibility of inference to the entire infant population of Brazzaville.

The hospital frequency estimated at $1.1 \%$ in this work is lower in Brazzaville than the previous work carried out in the same hospital: $1.8 \%$ and $2 \%$ [11.1]. Nevertheless, it is higher than those reported by ATEGBO in Gabon and KOUETA in Burkina-Faso: $0.4 \%$ and $0.3 \%$ [10.8]. This may be explained by the differences in the methods used in either studies particularly the type, the population and the study setting.

Petroleum ingestion is frequent in children with an average age of 20 months with a predominance in the age group of 13 to 30 months as reported by Mabiala et al. [1]: 19 to 24 months.

The predominance by age varies depending on the age group population of study. However, in most cases it has been reported a high incidence in children 
under five [8] [11] [14]. The classic male predominance already reported is found in this study [1] [8] [15] and is explained, among other things, by the hyperactive nature of the male child.

The predominant mode of ingestion, self-ingestion noted in $75.6 \%$ occurring between 2 and 6 p.m. is a known fact [9] [16] [17]. These hours correspond to the period of declining parental attention. Ingestion occurs more at home [1.9] as in $92.3 \%$ of children in this study. The petroleum storage container, often a bottle of drinking water, exposes the child if thirsty [18]. The harmful maneuvers used as the first line following ingestion of petroleum are the same and are the same as those reported by SYLLA [19], including administration of milk and attempted vomiting.

Clinically, pulmonary presentations are predominant [1] [16] [19]. They were noted in $75.1 \%$ of our patients. Their predominance is a consequence of inhalation of the volatile product, facilitated by coughing, vomiting maneuvers which contribute to the tracheobronchial passage of petroleum [20]. The pulmonary manifestations are associated with the occurrence of petroleum pneumopathy [21]. We noted $67.4 \%$ alveolar syndrome and $21 \%$ interstitial syndrome. The frequency of petroleum pneumopathy in this issueat $55.1 \%$ is similar to that reported by Siddiqui in Pakistan [20], lower than that of the study of Mahjoob in Iraq: $86 \%$ [22].

From a therapeutic sight, the antibiotherapy used in $89.7 \%$ of our patients and corticosteroids in $38.5 \%$ are well-known practices [16] [21]. Many authors recommend betalactams for the prophylactic treatment of secondary pulmonary infections. Others recommend them from the outset without proof of effectiveness. As for corticosteroids, no studies have shown their effectiveness on the intensity and or duration of symptoms [3] [23].

The outcome is generally good, but a $3.8 \%$ lethality has been noted as reported in some studies [1] [8] [11] [21] [22]. However, Gueye reports a lethality of more than $5 \%$ in relation to the delay in taking charge of the patient [16]. The wellknown factors associated with the occurrence of pneumonia [1] [22] [24] are: the amount ingested, the maneuvers performed at home and the existence of cough and neurological disorders.

\section{Conclusion}

Accidental ingestion of petroleum is still common among children in Brazzaville. The storage of petroleum in drinking water bottles is the determining factor. The relative lethality is important in part because of the always possible occurrence of pneumopathy, the main complication, of which the quantity of petroleum ingested and the maneuvers carried out at home are the most common associated factors.

\section{Conflicts of Interest}

The authors declare no conflicts of interest regarding the publication of this paper. 


\section{References}

[1] Mabiala-babela, J.R., Pandzou, N. and Moyen, G.M. (2010) La pathologieaccidentelle du nourrisson aux urgencespédiatriques du CHU de Brazzaville (Congo). Journal de Pédiatrie et de Puériculture, 23, 185-190. https://doi.org/10.1016/j.jpp.2010.04.002

[2] Diallo, T., Dénou, A., Coulibaly, B.F., Dakouo, B., Koumare, B.Y. and Maïga, A. (2016) Epidémiologie des intoxications aiguës chez les enfants de moins de 15 ans au Mali. Antropo, 35, 103-110.

[3] Lamour, C., Bouchaud, C., Doré, P., D’Arlhac, M. and Bodin, J. (2003) Pneumopathies par inhalation d'hydrocarbures volatiles. Revue des Maladies Respiratoires, 20, 959-964.

[4] Peden, M., Oyegbite, K., Ozane-Smith, J., et al. (2008) Rapport mondial sur la prévention des traumatismes chez l'enfant. Editions de l'OMS, Genève.

[5] Papeix, P.M. and Latriche, C. (1990) Pneumopathieaiguë des cracheurs de feu par inhalation de pétrole. Gazette médicale de France, 5, 83.

[6] Haas, C., Lebas, F.X., Lejeune, C., Lowenstein, W., Durand, H. and Hugues, F.C. (2000) Les pneumopathies par inhalation d'hydrocarbures. A propos de trois observations. Annales de Medecine Interne, 151, 438-447.

[7] Rapport CCTV (2009) Evaluation des risquesliés à l'utilisationd'allume-feu liquides et d'huiles pour lampes. Juin.

[8] Kouéta, F., Dao, L., Yé, D., Zeinabou, F. and Sawadogo, A. (2009) Les intoxications aiguesaccidentelles de l'enfant: Aspects épidémiologiques, étiologiques et évolutifs au CHU pédiatrique CHARLES-DE-GAULLE de Ouagadougou (Burkina Faso). Cahiers Santé, 19, 55-59. https://doi.org/10.1684/san.2009.0157

[9] Ake Assi, M.H., Timite-Konan, A.M., Adonis-Koffi, L.Y. and EhuaAmangoua, E.S. (2001) Aspects épidémiologiques des intoxications aiguës chez l'enfantenpédiatrie à Abidjan. Medecine d' Afrique Noire, 48, 457-460.

[10] Ategbo, S., Minto'o, S., Koko, J. and MengueMba-Meyo, S. (2012) Aspects épidémiologiques des accidents domestiques de l'enfant à Libreville (Gabon). Clinics in Mother and Child Health, 9, 1-3. https://doi.org/10.4303/cmch/C120201

[11] Ekouyabowassa, G., Oko, A., Okoko, A.R. and Moyen, G.M. (2008) Intoxications aigues chez l'enfant à Brazzaville. Rev Camessérie A, 6, 85-87.

[12] Fink, R. and Kosecoff, J. (1985) How to Conduct Surveys: A Step by Step Guide. Sage Publications Inc., London, 53-63.

[13] Huber, C., Huber-Braun, M.C., Desrentes, M. and Lautier, F. (1987) Les intoxications aiguës par le pétrole chez l'enfant au Gabon. Medecine d'Afrique Noire, 34, 8-9.

[14] Beaufils, F., et al. (1979) Intoxications aiguës par le pétrole et sesdérivés. La Revue du Praticien, 29, 1251-1257.

[15] Hazebrtoucq, G. (1995) Le pétrolelampant. Dorvaultl'officine. 23ème éd., Vigot, Paris, 1248-1249.

[16] Gueye, M., Fall, A.L., Sylla, A., Niouky, G., Diagne, N.R., Boiro, D., et al. (2014) Les intoxications aigues de l'enfant aux hydrocarbures à Dakar: Aspects épidémiologique, clinique, thérapeutique et évolutif. Medecine d' Afrique Noire, 61, 41-46.

[17] Djiibo, H., Badio, S., Guidah, S., Kamaye, I. and Toure, I.A. (2011) Les accidents domestiques chez les enfants de moins de 5ans: A propos de 752 casrecensés à l'hôpital national de Niamey. Journal Africain d Imagerie Médicale, 7, 3663-3667.

[18] Adonis-Koffy, L.Y. (1999) Les intoxications aiguës en pédiatrie au CHU de Yopou- 
gon. Côte d'Ivoire. Bulletin de la Société de Pathologie Exotique, 92, 2.

[19] Sylla, M., Coullibaly, Y., Dicko, F.T., Kourouma, N., Togo, B. and Keita, M.M. (2006) Intoxication aigueaccidentelle chez L'enfant au service de pédiatrie de l'hôpital GABRIEL TOURE. Mali Medical, 11, 50-53.

[20] Siddiqui, E.U., Razzak, A.J., Naz, F. and Khan, S.J. (2008) Les facteursassociés à l'ingestiond'hydrocarbures chez les enfants. Journal of Pakistan Medical Association, 58, 608-612.

[21] Bamouni, Y.A., Bonkoungou, P., Nacro, B. and Nagalo, K. (1999) Aspects radiologiques de l'intoxicationaigue au pétroleen milieu hospitalierpédiatrique au CHNSS de BOBO-DIOULASSO (Burkina-Faso). Medecine d' Afrique Noire, 46, 78-82.

[22] Al-Naddawi, M., Abdul-Qader Al-Chalabi, M. and Kamil, K.M. (2009) Kerosene Poisoning in Children. Le Journal Irakienmédical Post Doctorale, 4, 350-356.

[23] Balme, K.H., Zar, H., Swift, D.K. and Mann, M.D. (2015) The Efficacy of Prophylactic Antibiotic in the Management of Children with Kerosen Associated Pneumocytis: A Double-Blind Randomised Controlled Trial. Clinical Toxicology (Philadelphia, Pa.), 53, 789-796. https://doi.org/10.3109/15563650.2015.1059943

[24] Lifshitz, M., Sofer, S. and Gorodischer, R. (2003) Hydrocarbon Poisoning in Children: A 5 Years Retrospective Study. Wilderness and Environmental Medicine, 14, 78-82. https://doi.org/10.1580/1080-6032(2003)014[0078:HPICAY]2.0.CO;2 